\title{
Mucin expression in gastric- and gastro-oesophageal signet-ring cell cancer: results from a comprehensive literature review and a large cohort study of Caucasian and Asian gastric cancer
}

\author{
K. G. P. Kerckhoffs ${ }^{1} \cdot$ D. H. W. Liu ${ }^{1} \cdot$ L. Saragoni ${ }^{2} \cdot$ R. S. van der Post ${ }^{3} \cdot$ R. Langer ${ }^{4} \cdot$ M. Bencivenga $^{5} \cdot$ M. Iglesias $^{6}$. \\ G. Gallo ${ }^{7}$. L. C. Hewitt ${ }^{1}$. G. E. Fazzi ${ }^{1}$ - A. M. Vos ${ }^{3}$. F. Renaud ${ }^{8}$. T. Yoshikawa ${ }^{9} \cdot$ T. Oshima $^{10}$ - A. Tomezzoli ${ }^{11}$.

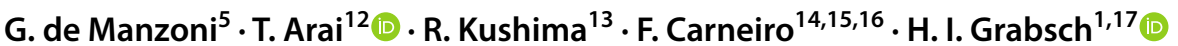

Received: 23 March 2020 / Accepted: 14 May 2020 / Published online: 2 June 2020

(c) The Author(s) 2020

\begin{abstract}
Background The literature on the prognostic relevance of signet-ring cell (SRC) histology in gastric cancer (GC) is controversial which is most likely related to inconsistent SRC classification based on haematoxylin-eosin staining. We hypothesised that mucin stains can consistently identify SRC-GC and predict GC patient outcome.

Methods We performed a comprehensive literature review on mucin stains in SRC-GC and characterised the mucin expression in 851 Caucasian GC and 410 Asian GC using Alcian Blue (AB)-Periodic Acid-Schiff (PAS), MUC2 (intestinal-type mucin), and MUC5AC (gastric-type mucin). The relationship between mucin expression and histological phenotype [poorly cohesive (PC) including proportion of SRCs, non-poorly cohesive (non-PC), or mucinous (MC)], clinicopathological variables, and patient outcome was analysed.

Results Depending on mucin expression and cut-offs, the positivity rates of SRC-GC reported in the literature varied from 6 to $100 \%$. Patients with MUC2 positive SRC-GC or SRC-GC with (gastro)intestinal phenotype had poorest outcome.

In our cohort study, PC with $\geq 10 \%$ SRCs expressed more frequently MUC2, MUC5AC, and ABPAS $(p<0.001, p=0.004$ and $p<0.001$, respectively). Caucasians with AB positive GC or combined ABPAS-MUC2 positive and MUC5AC negative had poorest outcome (all $p=0.002$ ). This association was not seen in Asian patients.

Conclusions This is the first study to suggest that mucin stains do not help to differentiate between SRC-GC and non-SRCGC. However, mucin stains appear to be able to identify GC patients with different outcome. To our surprise, the relationship between outcome and mucin expression seems to differ between Caucasian and Asian GC patients which warrants further investigations.
\end{abstract}

Keywords Gastric cancer $\cdot$ Signet-ring cells $\cdot$ Mucin $\cdot$ Histological phenotype $\cdot$ Survival

K. G. P. Kerckhoffs and D. H. W. Liu have contributed equally to this work.

Electronic supplementary material The online version of this article (https://doi.org/10.1007/s10120-020-01086-0) contains supplementary material, which is available to authorized users.

H. I. Grabsch

h.grabsch@maastrichtuniversity.nl

Extended author information available on the last page of the article

\section{Introduction}

Gastric cancer (GC) is a heterogenous disease with respect to epidemiology, morphology, and clinical behaviour. Despite declining incidence, GC remains one of the major causes of cancer-related death worldwide [1]. The incidence of poorly cohesive GC, including signet-ring cell (SRC) cancer, appears to be rising in the Western World [2, 3]. Several studies investigating the prognostic relevance of SRC histology reported conflicting results [4-8]. In some studies, SRC histology was associated with poor outcome, which was not confirmed in other studies [4-10]. Furthermore, it has been suggested that the relationship between SRC histology and outcome may depend on the disease stage in GC patients 
[11-17]. The clinical utility of the proportion of SRCs to predict response to preoperative chemo(radio)therapy in GC patients remains a matter of debate [18-24].

A recent expert panel hypothesised that these inconclusive results could be related to inconsistencies in the histological classification of SRC-GC [25]. Whilst SRC-GC have always been typed as diffuse-type cancers in the Lauren classification [26], the WHO definition of SRC-GC changed several times between the 1st edition in 1977 [27] and the 4th edition in 2010 [28]. Up to the 4th edition [27, 29, 30], when SRC-GC became a subcategory of poorly cohesive GC, SRC-GC was classified as a separate specific subtype of GC. Furthermore, the definition of the extent of SRCs to qualify as SRC-GC changed over the years from 'predominant', to more than 50\% SRCs in the 2nd edition WHO [29] and back to "predominantly" or "exclusively" in the 4th and 5th editions WHO [28, 31]. In an attempt to achieve a more consistent classification of SRC-GC, a multidisciplinary expert panel recently proposed specific cut-off values for the percentage of SRCs to distinguish bona-fide SRCGC (more than 90\% SRCs) from poorly cohesive GC with SRC component (between 10 and 90\% SRCs) and poorly cohesive GC not otherwise specified (less than 10\% SRCs) [25]. However, what remains particularly challenging is the unequivocal definition of what constitutes a SRC based on routine histology as exemplified by the 5 different types of SRCs described in the 3rd edition WHO [30]. Therefore, there remains an urgent clinical need to identify a specific biomarker for SRCs to standardise SRC-GC classification and establish the clinical importance of SRC-GC.

We hypothesised that (1) SRC containing gastric cancers have a different mucin expression compared to non-SRC gastric cancers, and (2) there is an association between SRC mucin expression, clinicopathological variables, and patient outcome.

The present study consists of two parts: (1) a comprehensive literature search to establish the frequency and clinical importance of mucin stains in SRC containing GC, and (2) a large cohort study in Asian and Caucasian GC where the histological phenotype was classified according to recently published consensus guidelines and the expression of several different mucin stains and its relationship to clinicopathological variables, patient outcome, and ethnicity was investigated.

\section{Materials and methods}

\section{Literature review}

A comprehensive literature search was conducted in the PubMed database including all publications up to October 1st, 2018 using synonyms and MESH terms for 'gastric' and 'signet-ring cell cancer' (see Online Resource 1). The title and abstract of resulting articles were screened based on the following inclusion criteria: the abstract or title mentioned SRC-GC, and results from histochemical or immunohistochemical mucin stains were reported separately for SRC-GC (see Fig. 1). If a study provided both, data from an SRC-GC and non-SRC-GC cohorts, only the SRC-GC data were extracted and analysed. We excluded studies reporting results from less than 10 SRC-GC, referring to hereditary diffuse GC, metastases with SRCs or unknown primary tumour, cell culture-based studies, animal studies, diagnoses based on cytology, and letters to editors containing no additional information. We also excluded studies where we were unable to retrieve the full-text version of the article, articles written in languages other than English or Japanese, and articles reporting only on gastro-oesophageal junction adenocarcinomas.

From the included studies, we extracted information about the definition of SRC-GC, classification system used, frequencies of positivity for histochemical and immunohistochemical mucin stains, differences in mucin expression between SRC-GC and relationship between mucin expression in SRC-GC, patient outcome, and other clinicopathological factors.

\section{Gastric cancer cohort study}

\section{Patients}

We included 851 Caucasian patients from Leeds Teaching Hospitals NHS Trust (LTHT), Leeds, UK, and 410 Asian patients from the Kanagawa Cancer Center Hospital $(\mathrm{KCCH})$, Yokohama, Japan, diagnosed with adenocarcinoma of the stomach or gastro-oesophageal junction. All patients underwent potentially curative gastrectomy or gastro-oesophagectomy with lymph node dissection. 76 patients had neoadjuvant chemotherapy. Clinical variables (age, sex, treatment, overall and 5-year survival, and mortality status) and histopathological variables [(y)pT, (y)pN, grade of differentiation, and tumour location] were retrieved from hospital records and pathology reports. The study protocol was approved by the relevant local ethics committees.

Tissue microarrays (TMAs) had been previously constructed from the resection specimen [32]. Three $0.7 \mathrm{~mm}$ cores where sampled from each LTHT GC and two $1.2 \mathrm{~mm}$ cores from each $\mathrm{KCCH}$ GC. The cores were taken from areas with the highest tumour density in both cohorts. Four micron thick sections were cut and stained with haematoxylin-eosin (H\&E) using a standard protocol and subjected to histochemical stains and immunohistochemistry as described below. Slides were scanned at $\times 40$ magnification using an Aperio XT Scanner (Aperio Technologies, Vista, CA, USA) at the University of Leeds slide scanning facility and viewed 
Fig. 1 Flowchart of included papers in literature study. $S R C$ signet-ring cell; $G C$ gastric cancer

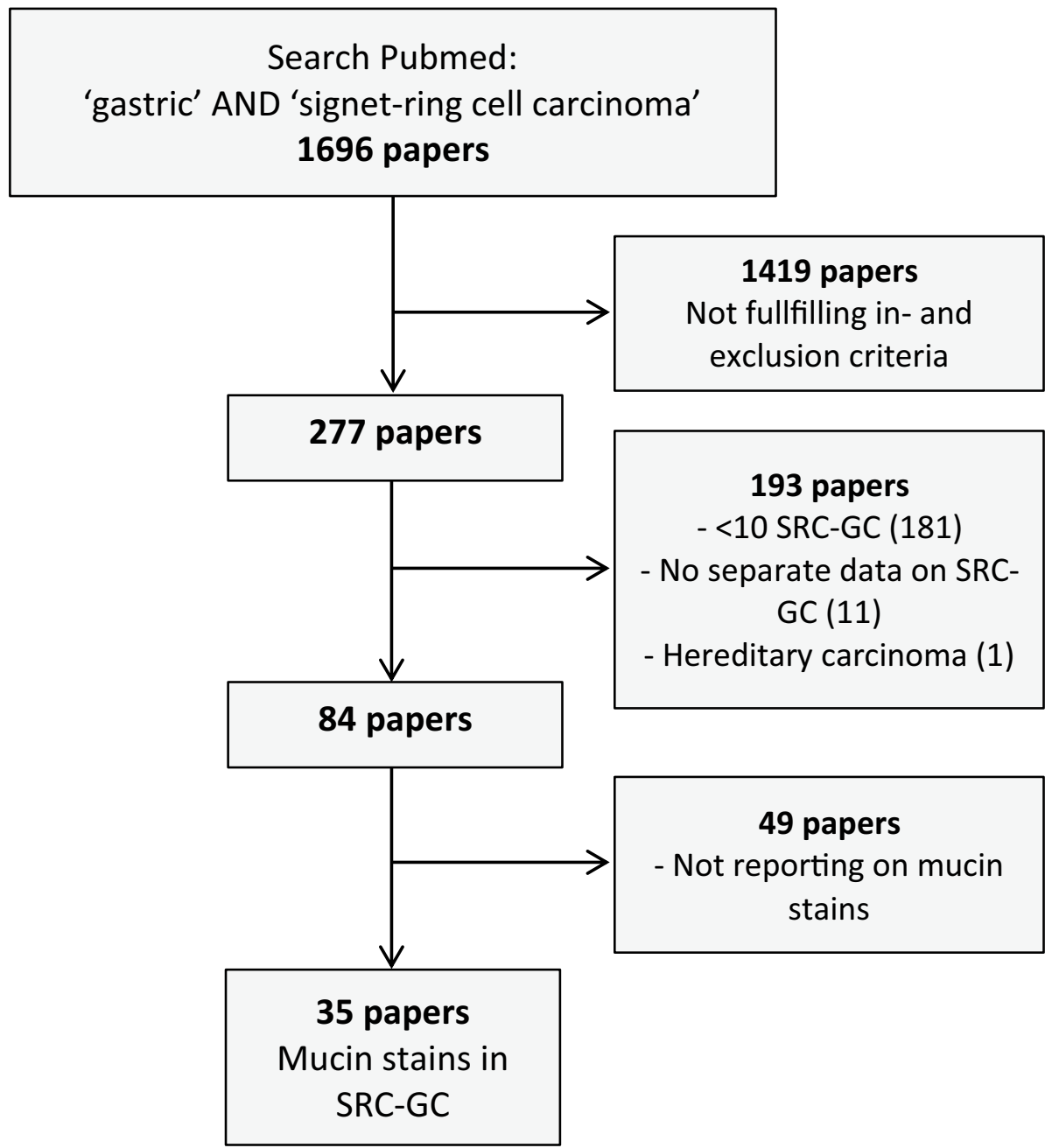

using Aperio ImageScope (version 12.3.2.8013). Scoring of the immunohistochemical stains was performed independently by two observers (D.L. and K.K.), and discrepant scores were reviewed and discussed jointly until agreement was reached.

\section{Histological classification}

The H\&E stain was used to classify GC based on 5th edition WHO Classification of Tumours of the Digestive System [31] in combination with the recently published consensus [25]. A poorly cohesive GC was defined as a cancer composed of isolated neoplastic cells or small aggregates of neoplastic cells [31]. To be classified as a mucinous GC, more than $50 \%$ of tumour area had to be occupied by pools of extracellular mucin [31]. GC not fulfilling the criteria for either poorly cohesive or mucinous GC were classified as non-poorly cohesive GC.

A classical SRC was defined as a cell with ample optically clear cytoplasmic mucin on H\&E stain and eccentrically placed nucleus. To compare the mucin expression characteristics of SRCs in poorly cohesive GCs with lookalikes SRCs in non-poorly cohesive and mucinous GCs, we decided to quantify the proportion of SRCs in all histological subtypes based on the H\&E appearance in 4 categories: $<10 \%$ SRCs, $\geq 10-50 \%$ SRCs, $\geq 50-90 \%$ SRCs, and $\geq 90 \%$ SRCs. This classification was performed blinded to (immuno)histochemical expression results or clinicopathological information.

\section{Mucin histochemistry and immunohistochemistry}

All GCs were stained for Alcian Blue (AB)-Periodic AcidSchiff (PAS) combined with pan-cytokeratin (CK-ABPAS), MUC2, and MUC5AC. We chose ABPAS to differentiate between acidic and neutral mucin. ABPAS stain was combined with immunohistochemistry for pan-cytokeratin to distinguish between mucin within epithelial cells, mucin within non-epithelial cells such as macrophages and extracellular mucin. We chose MUC2 as intestinal-type mucin stain and MUC5AC as gastric-type mucin stain, since these 
stains were most frequently used in studies in the literature [33-40].

After deparaffinisation in xylene and rehydration following a standard protocol, the pan-cytokeratin stain was performed first (see below) followed by the ABPAS stain. We used 1\% AB solution ( $\mathrm{pH} 2.5$ ), $1 \%$ periodic acid solution, and Schiff's solution following our routine laboratory protocol. Slides were dehydrated, coverslipped, and scanned.

For all antibodies, antigen retrieval was performed in a microwavable pressure cooker using $10 \mathrm{mM}$ citrate buffer, pH 6.0, and full pressure for $5 \mathrm{~min}$. Hydrogen peroxide and egg white solution were used to block endogenous peroxidase activity and endogenous biotin, respectively. The sections were incubated with antibodies against MUC2 (dilution 1:100, clone CCP58; Agilent/Dako), MUC5AC (dilution 1:100, clone CLH2; Agilent/Dako), and pancytokeratin (dilution 1:200, clone AE1/AE3; Agilent/Dako) for $1 \mathrm{~h}$ at $37^{\circ} \mathrm{C}$. Dako Real streptavidin-biotin detection kit was used as detection system and 3,3'-Diaminobenzidine (DAB) as chromogen (Dako) according to the instructions of the manufacturer. Slides were counterstained with Mayer's haematoxylin, dehydrated, coverslipped, and scanned.

\section{Scoring of mucin stains}

For all three stains (MUC2, MUC5AC, and ABPAS), a core with $\geq 10 \%$ stained tumour cells was classified as positive, irrespective of expression intensity. For this scoring, all tumour cells were considered irrespective of their morphology (signet-ring cell or not). If one of the cores of a case was classified as being positive, the whole case was classified as positive.

ABPAS-positive cores were initially subdivided into 5 categories: (1) AB positive; (2) PAS positive; (3) mixed positivity - same cells AB and PAS positive; (4) mixed positivity-different cells AB and PAS positive; (5) combination of categories 3 and 4 . A case was classified as positive for both ABPAS, if $\mathrm{AB}$ and PAS positivity was seen in the same core (category 3-5) or if one core was AB positive (category 1) and another core was PAS positive (category 2). As the number of cases in certain ABPAS subcategories was very small, we subsequently combined groups (see Table 1).

Furthermore, we created additional variables by combining the results of the different mucin stains (ABPAS, MUC2, and MUC5AC) (see Online Resource 2).

\section{Statistical analyses}

Data were analysed using SPSS Statistics for Windows version 25.0 (IBM, Armonk, NY, USA). Patient characteristics, histological tumour types, and mucin expression were compared between the LTHT and the KCCH cohorts using the Mann-Whitney $U$ test for continuous variables and the
Pearson Chi-square test for categorical variables. For the analysis of the association between histological phenotype and mucin expression, results from both cohorts (LTHT and $\mathrm{KCCH}$ ) were combined. Associations between mucin expression and clinicopathological variables were assessed using the Kruskal-Wallis test. For survival analyses, individual mucin expression and combinations of mucin expressions (see Online Resource 2) were used. Kaplan-Meier survival analysis and log-rank test were used to compare 5-year and overall survival between patients with different histological tumour types or different mucin expression. 16 LTHT patients and $60 \mathrm{KCCH}$ patients underwent neoadjuvant chemotherapy, respectively. To determine whether neoadjuvant treatment influenced the results, all analyses were repeated excluding these 76 patients. As all associations remained the same, we report here results based on the whole cohort. $p$ values $<0.05$ were considered statistically significant.

\section{Results}

\section{Literature review of mucin stains in gastric signet-ring cell cancers}

The literature search in PubMed resulted in only 35 studies published over a period of 40 years (between 1977 and 2017) (see Fig. 1). The median number of SRC-GC patients per study was 37 (range 11-317), and the percentage of SRC-GC within individual studies ranged from 7 to $100 \%$. The majority of studies $(n=25,71 \%)$ originated from Asia.

\section{Definition of gastric signet-ring cell cancers and classification system used}

The definition of SRCs and the classification system used varied between studies (see Tables 2 and 3). Some authors provided a very detailed description mentioning intracellular accumulation of PAS, AB, and/or mucicarmine positive mucin [41-44] together with an eccentric nucleus as defining factors [44] or described 'classical SRCs' next to small SRCs with deep eosinophilic cytoplasm and a round larger hyperchromatic nucleus [45]. Other authors neither described the definition of SRC nor mentioned the classification system used. Some studies used cut-off values to define SRC-GC, either in concordance with the 2 nd and 3rd editions WHO classification (50\% rule) [35, 36, 38, 46-51] or using the 4th edition WHO classification [28] (predominant or exclusive rule without specific percentage) [41, 42]. One of the studies used a cut-off value of $90 \%$ to define a GC as SRC-GC [53]. 
Table 1 Descriptive statistics of the two cohorts

\begin{tabular}{|c|c|c|c|c|c|c|c|}
\hline & \multicolumn{2}{|c|}{ Overall $(n=1261)$} & \multicolumn{2}{|c|}{ Caucasian $(n=851)$} & \multicolumn{2}{|l|}{ Asian $(n=410)$} & \multirow[t]{2}{*}{$p$ value } \\
\hline & $n$ & $\%$ & $n$ & $\%$ & $n$ & $\%$ & \\
\hline Gender (male) & 852 & 68 & 557 & 66 & 295 & 72 & $0.026^{*}$ \\
\hline Mean age (years) & 66.6 (SD 11.0) & & $68.2(\mathrm{SD} 10.8)$ & & 63.3 (SD 10.7) & & $<0.001 *$ \\
\hline T stage & & & & & & & $<0.001^{*}$ \\
\hline $\mathrm{T} 1$ & 131 & 11 & 96 & 12 & 35 & 9 & \\
\hline $\mathrm{T} 2$ & 146 & 12 & 84 & 11 & 62 & 15 & \\
\hline T3 & 307 & 26 & 252 & 33 & 55 & 13 & \\
\hline $\mathrm{T} 4$ & 600 & 51 & 343 & 44 & 257 & 63 & \\
\hline $\mathrm{N}$ stage & & & & & & & $<0.001 *$ \\
\hline N0 & 359 & 29 & 275 & 32 & 84 & 21 & \\
\hline N1 & 264 & 21 & 177 & 21 & 87 & 22 & \\
\hline $\mathrm{N} 2$ & 296 & 24 & 194 & 23 & 102 & 25 & \\
\hline N3 & 340 & 27 & 204 & 24 & 136 & 33 & \\
\hline Classification & & & & & & & 0.641 \\
\hline $\mathrm{PC}<10 \% \mathrm{SRCs}$ & 192 & 15 & 129 & 15 & 63 & 15 & \\
\hline $\mathrm{PC}>10 \% \mathrm{SRCs}$ & 67 & 5 & 46 & 5 & 21 & 5 & \\
\hline Non-PC $<10 \%$ SRCs & 905 & 72 & 608 & 71 & 297 & 72 & \\
\hline Non-PC $>10 \%$ SRCs & 38 & 3 & 23 & 3 & 15 & 4 & \\
\hline $\mathrm{MC}<10 \%$ SRCs & 14 & 1 & 9 & 1 & 5 & 1 & \\
\hline $\mathrm{MC}>10 \%$ SRCs & 27 & 2 & 22 & 3 & 5 & 1 & \\
\hline Non-informative & 18 & 1 & 14 & 2 & 4 & 1 & \\
\hline \multicolumn{8}{|l|}{ Mucins } \\
\hline MUC2 & & & & & & & $0.043 *$ \\
\hline Negative & 1050 & 83 & 698 & 82 & 352 & 86 & \\
\hline Positive & 173 & 14 & 129 & 15 & 44 & 11 & \\
\hline MUC5AC & & & & & & & $<0.001 *$ \\
\hline Negative & 844 & 67 & 544 & 64 & 300 & 73 & \\
\hline Positive & 387 & 31 & 289 & 34 & 98 & 24 & \\
\hline ABPAS & & & & & & & $0.037 *$ \\
\hline Negative & 974 & 77 & 674 & 79 & 300 & 73 & \\
\hline Positive & 255 & 20 & 159 & 19 & 96 & 23 & \\
\hline$* \mathrm{AB}$ positive & 62 & 5 & 47 & 6 & 15 & 4 & \\
\hline *PAS positive & 37 & 3 & 23 & 3 & 14 & 3 & \\
\hline *Mixed, same cells & 7 & 0.6 & 2 & 0.2 & 5 & 1 & \\
\hline *Mixed, different cells & 4 & 0.3 & 4 & 0.5 & 0 & 0 & \\
\hline *Mixed, both expressions & 145 & 12 & 83 & 10 & 62 & 15 & \\
\hline
\end{tabular}

$n$ number of cases, $S R C$ signet-ring cell, $P C$ poorly cohesive cancer, non- $P C$ non-poorly cohesive cancer, $M C$ mucinous cancer, $S D$ standard deviation

\section{Gastric signet-ring cell cancer and histochemical mucin stains}

We identified 12 studies reporting on histochemical mucin stains in SRC-GC published between 1977 and 2013. The median number of included SRC-GC cases was 28 (range 11-102).

Different studies used single stain or combination of stains to classify SRC-GC (see Table 4).

Three studies combined morphological features and histochemical mucin stains to classify SRC-GC into several subtypes. Kubota et al. [53] used AB, AB-PAS, and LNAase stains to classify 64 SRC-GC as type A (immature: PAS weak positive, $\mathrm{AB}$ negative, LNAase positive, small cell size, and high nuclear/cytoplasmic ratio), type $\mathrm{B}$ (intermediate: stronger PAS positivity, AB negative or weak positive, LNAase positive, and smaller nuclear/cytoplasmic ratio) or type $\mathrm{C}$ (mature: PAS strong positive, $\mathrm{AB}$ positive, and eccentric nucleus). The C-type was further divided in $\mathrm{C} 1$ and $\mathrm{C} 2$ subtypes with the $\mathrm{C} 1$ subtype showing weaker $\mathrm{AB}$ positivity combined with LNAase positivity and the $\mathrm{C} 2$ subtype showing stronger $\mathrm{AB}$ positivity 


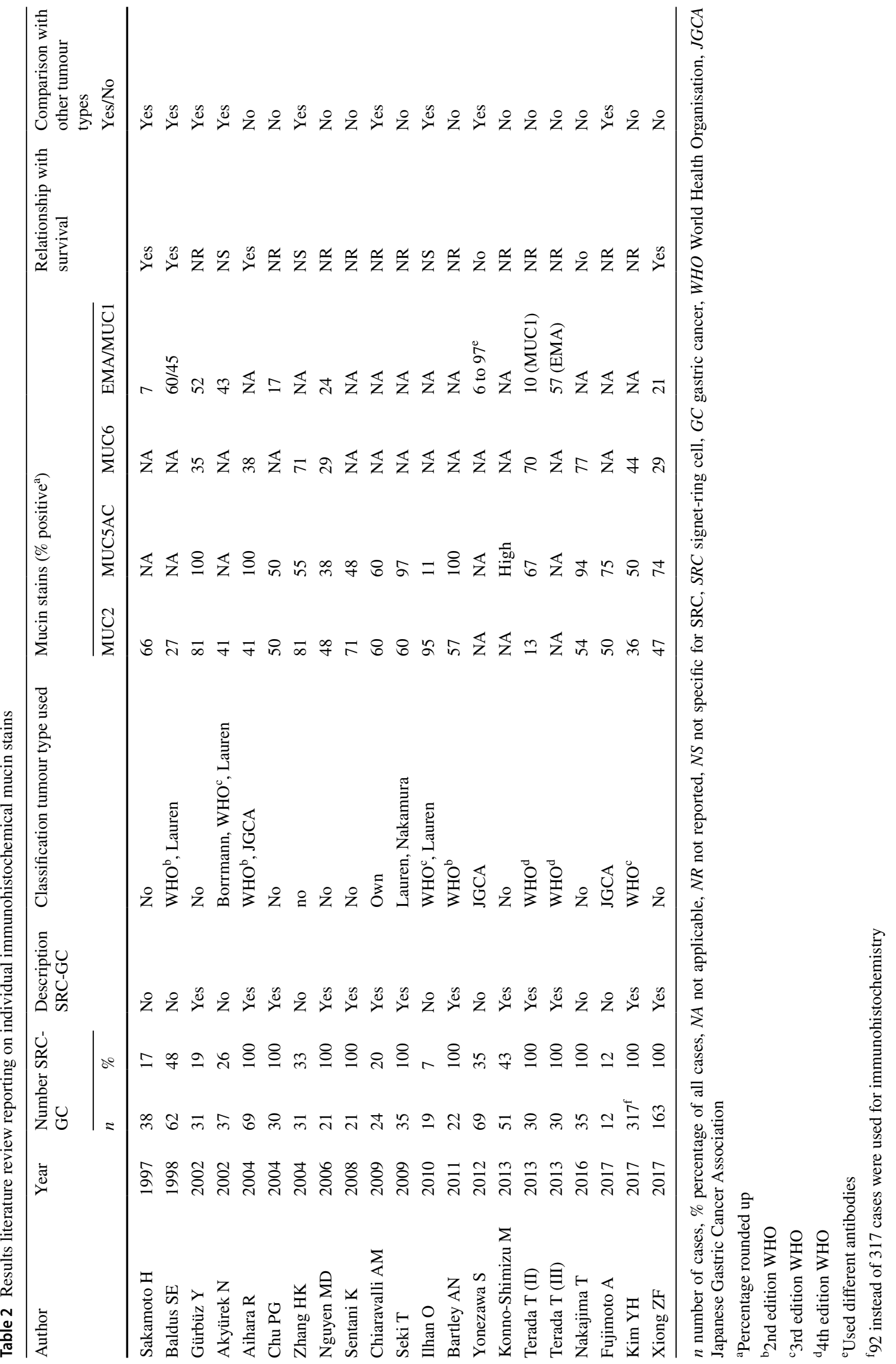


Table 3 Results from studies in the literature reporting on mucin phenotypes based on immunohistochemical mucin stains

\begin{tabular}{|c|c|c|c|c|c|c|c|c|c|c|c|}
\hline \multirow[t]{2}{*}{ Author } & \multirow[t]{2}{*}{ Year } & \multicolumn{2}{|c|}{$\begin{array}{l}\text { Number } \\
\text { SRC-GC }\end{array}$} & \multirow{2}{*}{$\begin{array}{l}\text { Descrip- } \\
\text { tion SRC- } \\
\text { GC }\end{array}$} & \multirow{2}{*}{$\begin{array}{l}\text { Classification } \\
\text { tumour type } \\
\text { used }\end{array}$} & \multicolumn{4}{|c|}{ Mucin phenotypes ( $\%$ of total SRC-GC ${ }^{a}$ ) } & \multirow{2}{*}{$\begin{array}{l}\text { Relationship } \\
\text { with survival }\end{array}$} & \multirow{2}{*}{$\begin{array}{l}\text { Comparison } \\
\text { with other } \\
\text { tumour types } \\
\text { Yes/No }\end{array}$} \\
\hline & & $n$ & $\%$ & & & $G$ & $I$ & GI/mixed & $U$ & & \\
\hline Bamba M & 2001 & 54 & 100 & Yes & JGCA & 28 & 2 & 69 & NA & Yes & No \\
\hline Tsukashita S & 2003 & 17 & 17 & No & NR & 77 & 0 & 0 & 23 & NR & Yes \\
\hline Aihara R & 2004 & 69 & 100 & Yes & $\mathrm{WHO}^{\mathrm{b}}, \mathrm{JGCA}$ & 60 & 0 & 41 & 0 & Yes & No \\
\hline Aihara R & 2005 & 69 & 54 & Yes & $\mathrm{WHO}^{\mathrm{b}}$ & 47 & 2 & 46 & 5 & Yes & Yes \\
\hline Ohkura Y & 2005 & 79 & 28 & No & No & $\begin{array}{l}\text { SRC: } 81 ; \\
\text { mixed: } 35\end{array}$ & $\begin{array}{l}\text { SRC: } 2 ; \\
\text { mixed: } 15\end{array}$ & $\begin{array}{l}\text { SRC: } 16 ; \\
\text { mixed: } 50\end{array}$ & 0 & NR & No \\
\hline Tian MM & 2007 & 66 & 100 & Yes & $\mathrm{WHO}^{\mathrm{c}}$ & 26 & 15 & 47 & 12 & Yes & No \\
\hline Nakajima T & 2016 & 35 & 100 & No & No & 0 & 0 & 35 & 0 & NR & No \\
\hline Xiong ZF & 2017 & 163 & 100 & Yes & No & 39 & 18 & 42 & NA & Yes & No \\
\hline
\end{tabular}

$n$ number of cases, \% percentage of all cases, $G$ gastric phenotype, $I$ intestinal phenotype, $G I$ gastrointestinal phenotype, $U$ unclassified, $N A$ not applicable, $N R$ not reported, SRC signet-ring cell, GC gastric cancer, WHO World Health Organisation, JGCA Japanese Gastric Cancer Association

${ }^{\text {a}}$ Percentages rounded up

${ }^{\mathrm{b}}$ 2nd edition WHO

c 3 rd edition WHO

Table 4 Histochemical mucin stains and detection purpose

\begin{tabular}{|c|c|c|}
\hline Stains & Purpose/specific cell-type & References \\
\hline Alcian blue (AB) & Identification of acid and neutral mucin; goblet cells & {$[39,47-49,51,52,55-57]$} \\
\hline Periodic acid-Schiff (PAS) with or without diastase & Identification of acid and neutral mucin & {$[39,47,48,50,51,56]$} \\
\hline High iron diamine (HID) with $\mathrm{AB}$ & Differentiating sulphomucin from sialomucin & {$[51,56]$} \\
\hline Galactose oxidase-Schiff (GOS) & $\begin{array}{l}\text { Identification of terminal } \beta \text {-galactose and } \beta-N \text { - } \\
\text { acetylgalactosamine; gastric surface mucous cells }\end{array}$ & {$[56,58]$} \\
\hline $\begin{array}{l}\text { Periodic acid-sodium borohydride-potassium } \\
\text { hydroxide (PA-SB-PH) }\end{array}$ & $\begin{array}{l}\text { Identification of sialic acid } O \text {-acylated side chain; goblet cells } \\
\text { in large intestine }\end{array}$ & {$[56]$} \\
\hline Mucicarmine & Acid mucin; goblet cells & {$[47,48]$} \\
\hline Paradoxical Concanavlin A stain (PCS) & $\begin{array}{l}\text { Detection of stable class III mucin; cardiac glands, mucous } \\
\text { neck cells, pyloric glands, and Brunner's glands }\end{array}$ & {$[56,58]$} \\
\hline LNAase & Marker enzyme for small intestine and intestinal metaplasia & [55] \\
\hline
\end{tabular}

combined with negative LNAase expression. Akamatsu et al. [54] used five histochemical stains (AB-PAS, HIDAB, GOS, PA-SB-PH-PAS, and PCS) to classify 31 SRCGC into 6 subtypes (1) surface mucous cell-type; (2) mucous neck cell-pyloric cell-type; (3) goblet cell (small intestine)-type; (4) goblet cell (large intestine)-type; (5) microcyst-type and (6) unclassified. Although different SRC sub types could be present in the same tumour, types $1,2,3$, and 4 were observed most frequently as the dominant cell type. In addition, the authors described the presence of the so-called intramucosal laminated structures (ILS) in SRC cancer distinguishing three types: complete (upper, middle, and lower layers of the mucosa), incomplete (upper and middle layers), and inverted (middle and lower layer) based on morphology and histochemical mucin expression. Tatematsu $[55,56]$ combined histochemical stains for PCS, GOS, and sialidase GOS with immunohistochemical stains for pepsinogen I and II to classify 127 SRC-GC as gastric phenotype, intestinal phenotype, or mixed gastrointestinal phenotype. The gastric phenotype was the most prevalent subtype (in both studies approximately $74 \%$ ).

However, the above mentioned detailed histomorphological subclassifications of SRC-GC have not been validated in any subsequent studies and the relationship with clinical variables has only been investigated by Akamatsu [54] who did not find any associations. 


\section{Frequency of histochemical mucin positivity in gastric signet-ring cell cancers}

Fujiyoshi et al. [43] categorised SRCs into 'classical' (33.3\%) and 'non-classical' based on AB positivity, whereas Bakkelund et al. [44] used PAS positivity as defining feature of SRCs, although the amount of PAS positive material varied between SRCs in the same GC and between GCs. Work by Terada et al. [41, 42] suggested that SRCs were positive for PAS-D, AB and mucicarmine, whereas Santini et al. [45] showed that $51 \%$ of SRC-GCs were positive for PAS, AB, and high-iron diamine (HID), $12 \%$ positive for $\mathrm{AB}$ or PAS and HID, and $37 \%$ showed PAS positivity only. Takenoshita et al. [57] compared PAS and AB positivity between 'pure' SRC-GC and tubular or poorly differentiated GC containing SRCs. All pure SRC-GC were strongly PAS positive and $71 \%$ were also strongly $\mathrm{AB}$ positive. Interestingly, the $\mathrm{AB}$ and PAS positivity rate was similar in SRC containing tubular or poorly differentiated GCs, and only the expression intensity was found to be lower. Furthermore, SRC-GC seemed to have stronger $\mathrm{AB}$ expression compared to PAS expression $(p<0.01)$ [57].

In summary, the frequency of AB positive SRC-GC varied from 56\% [45] to 64\% [58], and PAS positivity varied from $61 \%$ [57] to $95 \%$ [45]. One study described HID positivity in $63 \%$ of GCs [45].

\section{Relationship of histochemical mucin positivity with clinicopathological variables}

We did not find any study investigating the relationship between $\mathrm{AB}$ and/or PAS positivity and clinicopathological variables or patient outcome.

A single study combined histochemical mucin stains (PCS, GOS, and sialidase GOS) and immunohistochemical stains [pepsinogen II, SH-9 (surface mucous cell stain), and TKH-2 (goblet cells and parietal cell stain)] to define the phenotype of 203 SRC-GC as gastric [ $>90 \%$ surface mucous cell type or pyloric gland cell type, $n=130(64 \%)$ ], intestinal [ $>90 \%$ goblet cell type or microcyst type, $n=4(2 \%)$, or mixed gastrointestinal [10-90\% gastric and/or intestinal cell types, $n=69(34 \%)$ ] [46]. The proportion of gastric phenotype SRC-GC decreased with increasing depth of invasion, whereas the proportion of mixed phenotype SRC-GC increased with depth of invasion. This could suggest that the progression of SRC-GC may be associated with a phenotypic shift from gastric to intestinal-type mucin expression.

\section{Immunohistochemical stains for mucin expression of gastric signet-ring cell cancers}

Twenty-six studies using immunohistochemistry were published between 1997 and 2017, and the median (range) number of SRC-GC was 31 (12-317). The results are summarised in Tables 2 and 3.

We noted a wide variation of cut-off values used to classify a cancer as being positive for a particular marker which most likely explains the wide range in reported positivity frequencies. MUC4, STn, and trefoil factor family peptide (TFF) 1 and TFF3 were only investigated in a single study and reported to be positive in 57\% [58], 57\% to $71 \%$ [59], 33.3\% and $100 \%$ [60] SRC-GC, respectively.

The frequency of single mucin stain positive SRC-GC ranged from $13 \%$ [41] to 95\% [51] for MUC2, 11\% [51] to $100 \%$ [35, 49, 61] for MUC5AC, $29 \%$ [58] to $71 \%$ [62] for MUC6 and 6\% [63] to 97\% [63] for EMA/MUC1. A single study by Kim et al. [50] compared the frequency of mucin expression between pure SRC-GC and SRC-GC combined with $<50 \%$ tubular or papillary component and did not find any differences for MUC2, MUC5AC, or MUC6.

Some studies suggested a relationship between mucin expression and depth of invasion. MUC5AC expression was seen in tumour cells in the superficial [33, 35, 49] part of the gastric wall, whereas tumour cells positive for MUC6 [35] or PCS III [33] were more frequently found in deeper parts of the wall. The location of MUC2 positive tumour cells appeared to be more variable and could be superficially [49], central/marginal [35], or in a mosaic pattern [33].

Several studies [33-40] investigated combinations of mucin stains in SRC-GC (see Table 3) and described four SRC-GC phenotypes: gastric (G), intestinal (I), gastrointestinal/mixed (GI), and unclassified (UC). The G-type showed expression of one or more gastric mucin stains (MUC5AC and/or MUC6 and/or PCSIII and/or M-GGMC-1) and absence of intestinal-type mucin stain MUC2; the I-type showed expression of intestinal mucin stains and absence of gastric mucin stains; the GI-type showed a combination of stains and the unclassified type is negative for any mucin stains (for details, see Online Resource 3). However, the reported frequency of these phenotypes in SRC-GC varied: G-type ranged from 0\% [39] to $81 \%$ [37], I-type from $0 \%$ [34, 35, 39] to $18 \%$ [40], and GI-type $0 \%$ [34] to 69\% [33]. Aihara et al. [36] found a difference in mucin phenotype when comparing SRC-GC with non-SRC-GC (SRC-GC: 41 G-type, 28 GI-type; nonSRC-GC: 20 G-type, 31 GI-type, $p=0.029)$.

Seki et al. [64] divided 35 intramucosal SRC-GC in three groups based on the type of ILS (as described by Akamatsu et al. [54]): complete type only (group A-40\%), both complete and incomplete type (group $\mathrm{B}-49 \%$ ), and incomplete type only (group $\mathrm{C}-11 \%$ ). MUC2 expression was different $(29 \%, 76 \%$, and $100 \%$ of $\mathrm{GC}$ in groups $\mathrm{A}, \mathrm{B}$, and $\mathrm{C}$, respectively. $p=0.0006$ ). 
Relationship between immunohistochemical mucin stains and clinicopathological variables including patient outcome

Some studies reported a poorer outcome for patients with MUC1 positive SRC-GC [48, 60]. GI and I-type SRC-GC were associated with poorer overall outcome compared to $\mathrm{G}$ and UC-type ( $31.82 \%$ vs. $68.75 \%, p=0.0146$ ) [38]. No association was found between patient outcome and MUC2 or STn positivity [60].

MUC2 positive or GI-type SRC-GC was associated with larger tumour diameter [35, 36, 38], increased depth of invasion $[35,36,38,40]$, presence of lymph-node metastases [38], or lymphovascular invasion [36, 38, 40]. Patients with G-type SRC-GC had smaller tumours, lower rates of lymph-node metastasis, or vascular invasion compared to other phenotypes (both $p<0.01$ ) [38]. Furthermore, Xiong et al. [40] found that MUC5AC expression was inversely associated with depth of invasion. Bamba et al. [33] showed that mucosal tumour size was related to abundance of I-type tumour cells, whereas no such relationship was seen for tumour cells in deeper parts of the wall.

To the best of our knowledge, the relationship between mucin positivity and response to therapy has not been investigated.

\section{Comparison of immunohistochemical mucin stains between gastric signet-ring cell cancer and other histological tumour types}

The relationship between immunohistochemical mucin expression and histological tumour type in GC is still controversial. Some studies reported that tubular/papillary/ glandular adenocarcinomas were more frequently MUC1 [47, 48, 59, 61, 62], MUC2 [47, 48] and/or MUC5AC [51] positive compared to SRC-GC. Whereas other studies found that SRC-GC were more often MUC2 [51, 59, 60, 65], TFF3 [60], or MUC5AC [61, 65] positive compared to other types of GC, Ilhan et al. [51] found no relationship of MUC1 expression and histological tumour type. Zhang [62] did not find an association between MUC2, MUC5AC, and MUC6 expression and histological tumour type, whereas other studies showed that MUC2 expression was associated with mucinous cancers [51, 61, 62].

In conclusion, the existing number of studies on (immuno)histochemical mucin expression in SRC-GC is limited, and results are controversial most likely related to sample size, the use of different mucin stains, or combinations of stains and variable cut-offs. We noted differences in frequencies of mucin positivity in SRC-GCs as well as differences in the reported association with clinicopathological variables including patient outcome. The majority of published studies were performed using material from Asian
GC patients; thus, it is not clear whether results in Caucasian patients would be similar.

All the above motivated us to complement the comprehensive literature review with a large cohort study on more than 1000 patients with gastric or gastro-oesophageal cancers.

\section{Results from our own gastric and gastro-oesophageal cancer cohort study}

This study included material from 958 (76\%) patients with GC and 303 (24\%) patients with junctional/lower oesophageal adenocarcinoma. For clinicopathological and demographic cohort characteristics, see Table 1. This cohort included 851 Caucasian patients (LTHT cohort: 709 gastric and 142 junctional/lower oesophageal cancer) and 410 Asian patients (KCCH cohort: 249 gastric and 161 junctional/ lower oesophageal cancer).

\section{Frequency of mucin positivity}

Using the presence of expression in more than $10 \%$ tumour cells as cut-off for all 3 stains (MUC2, MUC5AC, AB/PAS), $670(53 \%)$ cancers were classified as 'triple negative'. 172 (14\%) cancers were classified as MUC2 positive, 383 (31\%) MUC5AC positive, and 253 (20\%) AB and/or PAS positive (see Table 1). $145 \mathrm{AB}$ and/or PAS positive cancers showed a mixed expression with both, the same and different cells being positive for $\mathrm{AB}$ and/or PAS. 330 (26\%) cancers were positive for only one of the three mucin stains (48 (4\%) only MUC2 positive, 217 (17\%) only MUC5AC positive, and 65 (5\%) only ABPAS positive). 176 (14\%) cancers were positive for two mucin stains whereby combined positivity of MUC5AC and ABPAS was most frequently seen (94 (8\%) cancers). 42 (3\%) cancers were triple positive (see also Online Resource 2).

\section{Histological phenotypes and associations with mucin stains}

$259(21 \%)$ cancers were classified as poorly cohesive, 943 (75\%) as non-poorly cohesive, and 41 (3\%) as mucinous. An overview of results from the non-poorly cohesive and mucinous cancers can be found in Table 1 and Fig. 2. In the group of poorly cohesive cancers, 192 (74\%), 36 (14\%), 21 (8\%), and 10 (4\%) cancers contained $<10 \%$ SRCs, $\geq 10-50 \%$ SRCs, $\geq 50-90 \%$ SRCs, and $\geq 90 \%$ SRCs, respectively. Signet-ring cells were seen in mucinous cancers: $<10 \%$ SRCs $(n=14,34 \%), \geq 10-50 \%$ SRCs $(n=12,29 \%), \geq 50-90 \%$ SRCs $(n=9,22 \%)$, and $\geq 90 \%$ SRCs $(n=6,15 \%)$. As expected, the number of non-poorly cohesive cancers with cells looking like signet-ring cells was very low, only 38 (3.8\%) cancers contained more than $10 \%$ lookalike SRCs, 

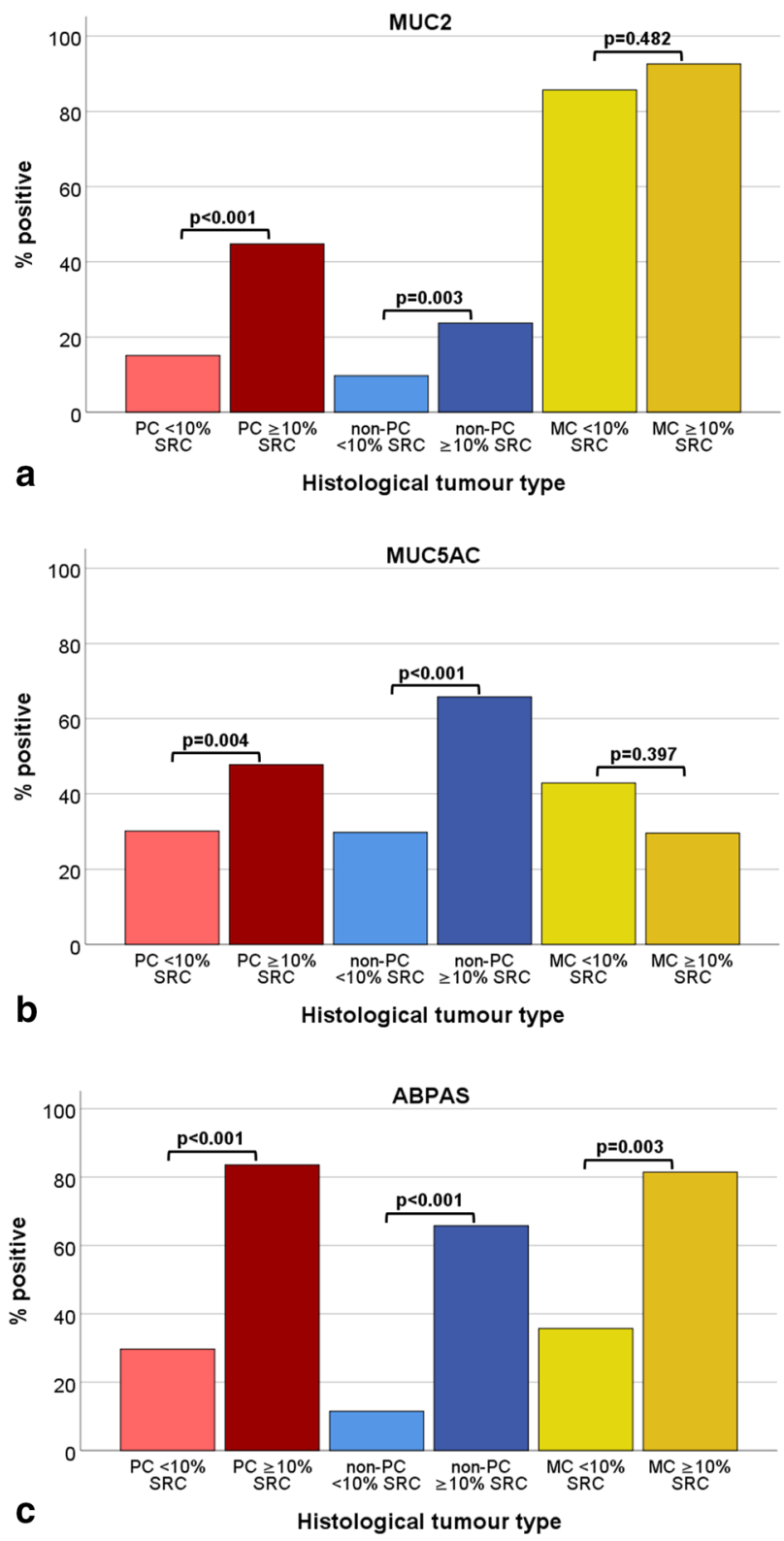

Fig. 2 Mucin expression in association with histological tumour type. a MUC2; b MUC5AC; c ABPAS. For PC and non-PC cases with $\geq 10 \%$, RCs showed more MUC2 $(p<0.001$ and $p=0.003)$, MUC5AC $(p=0.004$ and $p<0.001)$, and ABPAS $(p<0.001$ and $p<0.001)$ positivity compared to cases with $<10 \%$ SRCs. MC showed high MUC2 expression. MC with $\geq 10 \%$ SRCs were more often ABPAS positive compared to MC with $<10 \%$ SRCs $(p=0.003)$. $P C$ poorly cohesive cancer; non- $P C$ non-poorly cohesive cancer; $M C$ mucinous cancer; $S R C$ signet-ring cell

and none of the non-poorly cohesive cancers contained more than $50 \%$ lookalike SRCs.

Because of relatively small number of cases in subgroups, we compared poorly cohesive cancer with $<10 \%$ SRCs
( $n=192,15 \%)$, poorly cohesive cancer with $\geq 10 \%$ SRCs ( $n=67,5 \%$ ), non-poorly cohesive cancer with $<10 \%$ SRCs ( $n=905,72 \%)$, non-poorly cohesive cancer with $\geq 10 \%$ SRCs $(n=38,3 \%)$, mucinous cancer with $<10 \%$ SRCs $(n=14,1 \%)$, and mucinous cancer with $\geq 10 \%$ SRCs $(n=27$, $2 \%$ ) (see also Table 1).

Both, poorly cohesive and non-poorly cohesive cancers with $\geq 10 \%$ SRCs, were more frequently MUC2, MUC5AC, or ABPAS positive compared to cancers with $<10 \%$ SRCs (see Fig. 2). MUC2 was highly expressed in all mucinous cancers irrespective of the percentage of SRCs. Mucinous cancers with $<10 \%$ SRCs were less often ABPAS positive compared to mucinous cancers with $\geq 10 \%$ SRCs.

\section{Comparison between the LTHT cohort and the $\mathrm{KCCH}$ cohort}

The proportion of cancers with a particular histomorphological phenotype was similar in the LTHT and KCCH cohorts (see Online Resource 4). In both cohorts, non-poorly cohesive cancers were the most common histological subtype [LTHT $n=608$ (71\%); KCCH $n=297$ (72\%)]. MUC2- and MUC5AC-positive cancers were more frequent in the LTHT cohort (MUC2 LTHT $n=129$ (15\%) vs. KCCH $n=44$ (11\%), $p=0.043$; MUC5AC LTHT $n=289$ (34\%) vs. $\mathrm{KCCH} n=98$ (24\%), $p<0.001$ ), whereas ABPAS-positive cancers were more frequent in the $\mathrm{KCCH}$ cohort ( $\mathrm{KCCH} n=96(23 \%)$ vs. LTHT $n=159(19 \%) ; p=0.037)$ (see also Table 1).

$\mathrm{AB}$ positivity was associated with worse 5-year survival only in the LTHT cohort ( $p=0.002)$ (see Fig. 3). PAS, MUC2, or MUC5AC positivity was not related to outcome in any of the cohorts. Presence of combined ABPAS positivity, MUC2 positivity, and MUC5AC negativity $(n=35,4 \%)$ was related to poorer 5-year survival in the LTHT cohort $(p=0.002)$ (see Fig. 3 and Online Resource 5). No other associations with patient outcome were found in either cohort.

\section{Discussion}

There is an on-going debate whether patients with signetring cell (SRC) type gastric or gastro-oesophageal cancer have a different prognosis and response to chemotherapy [12-18] and, therefore, should be treated differently to patients with other gastric cancer (GC) subtypes. The inconsistent results reported in the literature could be related to the fact that the histopathological classification of SRC-GC can be challenging. This is due to the variable morphological appearances of individual SRCs [54-56] which may or may not be recognised as SRCs by some investigators [54, 54], as well as changing criteria in the WHO classification over the last decades [27-31]. Whilst an expert panel recently 
proposed cut-offs to enable separating pure SRC-GC $(\geq 90 \%$ SRCs) from GC with an SRC component, a biomarker to unequivocal identify SRC-GC would be of potential great value to clinicians and patients.

In search of a potential promising biomarker, we decided to focus on mucin-related stains as mucin appeared to be a defining characteristic of SRCs. Our group was the first to conduct a comprehensive literature review into the reported frequency and clinical importance of different mucin stains in SRC-GC. To our surprise, the number of studies describing (immuno)histochemical mucin expression in SRC-GC was very limited and results varied between studies making firm conclusions difficult. However, the existing literature seemed to suggest that mucin is not only present in SRC-GC, but can also be seen in other types of GC [47, 51, 59, 61, 62]. Furthermore, some SRC-GC appeared to contain no mucin $[34,35,39]$. Similarly to the well described morphological heterogeneity of GC, we found evidence that combinations of different kinds of mucins can be seen in the same GC [33, $35-40,45]$. Our literature review supports the previous suggestion of an expert panel that inconsistent clinicopathological findings can at least partly be explained by differences in the histological haematoxylin-eosin-based classification of SRC-GC together with different cut-off values used for considering a stain positive. Furthermore, even if the same cut-off value was used, results remained contradictory [39, $40,48,49,52,62,63]$ which could be related to the use of different primary antibodies [64]. When comparing reported results from Asian and Caucasian SRC-GC [34, 39, 41, 49, $58,62]$, we saw similar wide ranges of mucin positivity, suggesting that differences might not be simply related to ethnic origin of the cancers. Sampling of the tumours (luminal versus centre versus invasive front) could potentially explain different results in mucin expression as it has been reported by several investigators that intramucosal SRC-GC showed a 'layered structure' both morphologically and (immuno) histochemically [33, 35, 49]. Mucin characteristics of SRCGC varied depending on tumour size and disease stage [46, 66], thus results might vary depending on the case selection for the study $[35,36,38,46]$.

In order to close the gap in the current literature revealed by our comprehensive review, we decided to conduct our own gastric and gastro-oesophageal cohort study into mucin stains. Our study is the largest study to date where all cancers were re-classified in a standardised manner according to WHO classification and recent consensus [25]. Furthermore, our study is the first study to include both, Asian and Caucasian patients, enabling us to directly compare patient characteristics, histological tumour types, mucin expression, and relationship between mucin expression and patient outcome. Previous studies had either investigated Caucasian cohorts or Asian cohorts.

Our study provides further evidence that there is no (immuno)histochemical mucin stain unique to SRC cancer, since (1) a proportion of SRC containing GC was negative for the (immuno)histochemical mucin stains and (2) a relatively large percentage of GC without SRCs were positive for one or more mucin stains, similarly to what had been reported in the literature $[47,48,51,59-62,65]$. However, this is the first study to suggest that the mucin expression might be related to the quantity of SRCs within a given tumour as we saw more frequently mucin expression in poorly cohesive GC containing $\geq 10 \%$ SRCs.

When directly comparing Caucasian (LTHT) and Asian (KCCH) GC cohorts, MUC2 and MUC5AC positivity was more frequent in the LTHT cases, whereas ABPAS positivity was more frequent in the $\mathrm{KCCH}$ cases. This is the first study to report a relationship between $\mathrm{AB}$ positivity and outcome in $\mathrm{GC}$ patients. Most interestingly, $\mathrm{AB}$ positivity alone or in combination with other mucin expressions was only related to poor outcome in Caucasian GC providing further support for the hypothesis that different outcome in Caucasian and Asian GC patients may be related to an underlying biological difference [67]. As AB stains acidic mucins which are considered to be present in an intestinal phenotype, our finding would support the described association between (gastro) intestinal mucin phenotype and unfavourable outcome [38]. Due to relatively low patient numbers in mucin-defined subgroups, we were unable to explore whether the AB expression related outcome difference between cohorts was related to a different disease stage mix.

Based on the literature review and the results of our cohort study, we had to reject our first working hypothesis and conclude that SRC containing GC do not have a different mucin expression compared to non-SRC-GC. Further studies are needed to address this clinical need. On the other hand, results reported in the literature and from our own cohort study confirmed a relationship between SRC mucin expression and patient outcome in the surgery alone setting. Furthermore, our cohort study suggests that irrespective of histological phenotype, the mucin expression is different in Caucasian and Asian GC patient and is associated differently with outcome in different ethnic groups.

We recommend further studies comparing Caucasian with Asian GC to validate our findings and explore underlying molecular mechanisms for difference in mucin expression and outcome. Also, we recommend investigating whether the different mucin expression in SRC containing GC is related to variable treatment response. 
LTHT cohort

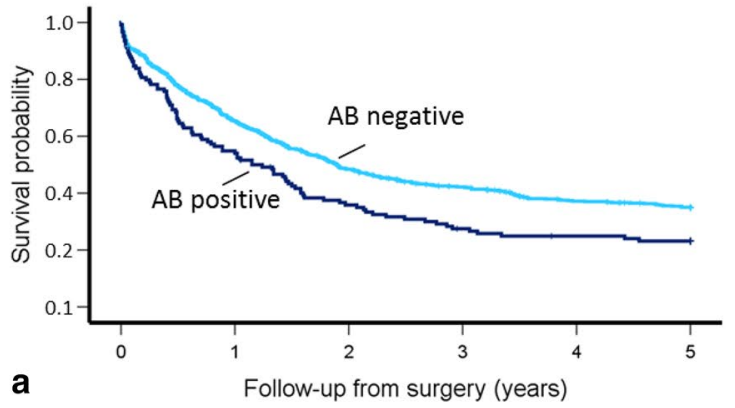

$\mathrm{KCCH}$ cohort

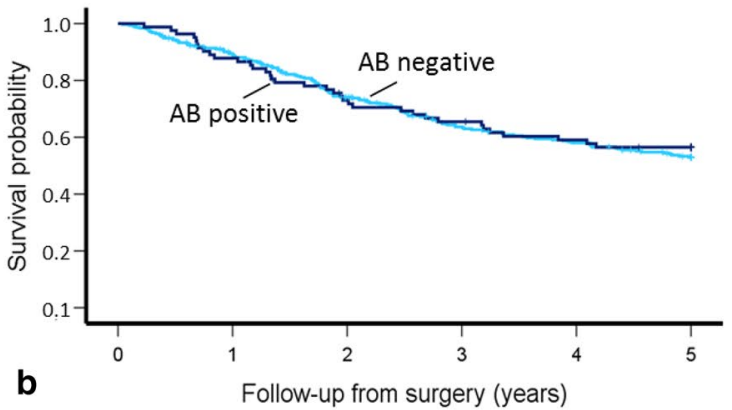

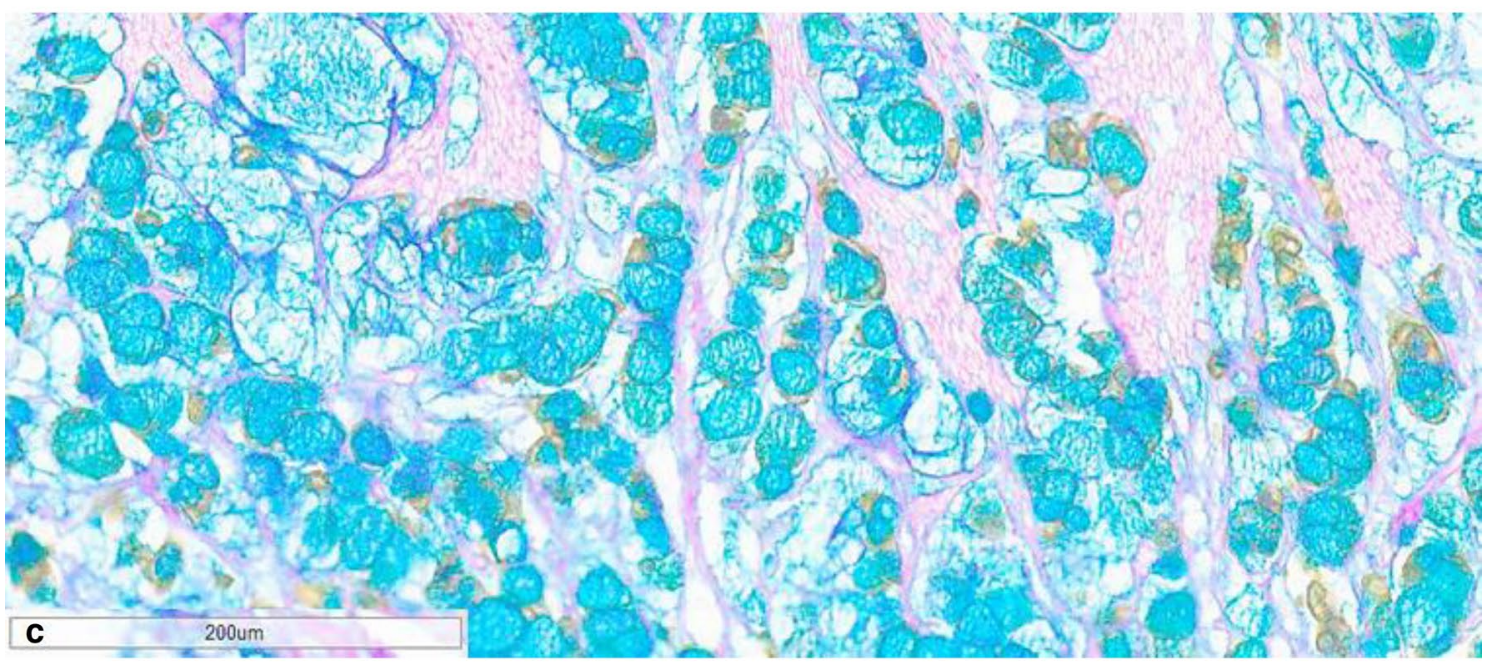

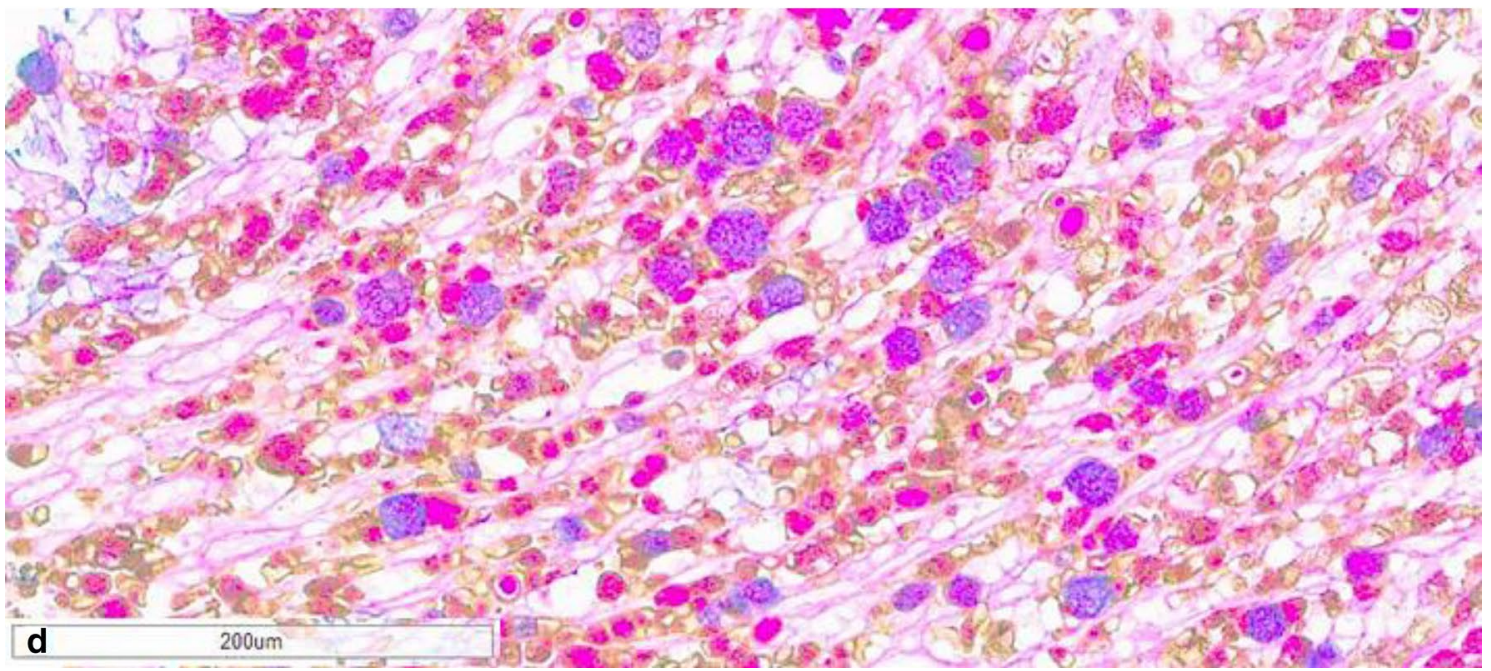

Fig. 3 Kaplan-Meier plots showing probability of 5-year survival stratified by $\mathrm{AB}$ expression and cohort $\mathbf{a}$ and $\mathbf{b}$ Kaplan-Meier survival analysis showed in the LTHT cohort significantly worse outcome in $\mathrm{AB}$ positive $\mathrm{GC}(p=0.002)$, this was not seen in the $\mathrm{KCCH}$ cohort. $\mathbf{c}$
Example of CK-ABPAS stain showing positivity for AB (blue staining). $\mathbf{d}$ Example of CK-ABPAS stain showing positivity for PAS and combined AB-PAS positivity (pink and purple staining respectively) 
Acknowledgements KGP Kerckhoffs and DHW Liu would like to thank the British Division of the International Academy of Pathology for the travel grant and the third poster price of the Leeds Pathology 2019 meeting in Harrogate.

Funding No funding.

\section{Compliance with ethical standards}

Conflict of interest The authors declare that they have no conflict of interest.

Open Access This article is licensed under a Creative Commons Attribution 4.0 International License, which permits use, sharing, adaptation, distribution and reproduction in any medium or format, as long as you give appropriate credit to the original author(s) and the source, provide a link to the Creative Commons licence, and indicate if changes were made. The images or other third party material in this article are included in the article's Creative Commons licence, unless indicated otherwise in a credit line to the material. If material is not included in the article's Creative Commons licence and your intended use is not permitted by statutory regulation or exceeds the permitted use, you will need to obtain permission directly from the copyright holder. To view a copy of this licence, visit http://creativecommons.org/licenses/by/4.0/.

\section{References}

1. Ferlay J, Soerjomataram I, Dikshit R, Eser S, Mathers C, Rebelo $\mathrm{M}$, et al. Cancer incidence and mortality worldwide: sources, methods and major patterns in GLOBOCAN 2012. Int J Cancer. 2015;136(5):E359-E386. https://doi.org/10.1002/ijc.29210.

2. Wu H, Rusiecki JA, Zhu K, Potter J, Devesa SS. Stomach carcinoma incidence patterns in the United States by histologic type and anatomic site. Cancer Epidemiol Biomarkers Prev. 2009;18(7):1945-52. https://doi.org/10.1158/1055-9965.

3. Henson DE, Dittus C, Younes M, Nguyen H, Albores-Saavedra J. Differential trends in the intestinal and diffuse types of gastric carcinoma in the United States, 1973-2000: increase in the signet ring cell type. Arch Pathol Lab Med. 2004;128(7):765-70.

4. Kim JP, Kim SC, Yang HK. Prognostic significance of signet ring cell carcinoma of the stomach. Surg Oncol. 1994;3(4):221-7.

5. Kunisaki C, Takahashi M, Nagahori Y, Fukushima T, Makino H, Takagawa R, et al. Risk factors for lymph node metastasis in histologically poorly differentiated type early gastric cancer. Endoscopy. 2009;41(6):498-503. https://doi.org/10.1055/s-0029-12147 58.

6. Maehara Y, Sakaguchi Y, Moriguchi S, Orita H, Korenaga D, Kohnoe S, et al. Signet ring cell carcinoma of the stomach. Cancer. 1992;69(7):1645-50.

7. Taghavi S, Jayarajan SN, Davey A, Willis AI. Prognostic significance of signet ring gastric cancer. J Clin Oncol. 2012;30(28):3493-8. https://doi.org/10.1200/jco.2012.42.6635.

8. Zhang M, Zhu G, Zhang H, Gao H, Xue Y. Clinicopathologic features of gastric carcinoma with signet ring cell histology. J Gastrointest Surg. 2010;14(4):601-6. https://doi.org/10.1007/ s11605-009-1127-9.

9. Li C, Kim S, Lai JF, Hyung WJ, Choi WH, Choi SH, et al. Advanced gastric carcinoma with signet ring cell histology. Oncology. 2007;72(1-2):64-8. https://doi.org/10.1159/00011 1096.
10. Piessen G, Messager M, Leteurtre E, Jean-Pierre T, Mariette C. Signet ring cell histology is an independent predictor of poor prognosis in gastric adenocarcinoma regardless of tumoral clinical presentation. Ann Surg. 2009;250(6):878-87. https://doi. org/10.1097/SLA.0b013e3181b21c7b.

11. Bamboat ZM, Tang LH, Vinuela E, Kuk D, Gonen M, Shah MA, et al. Stage-stratified prognosis of signet ring cell histology in patients undergoing curative resection for gastric adenocarcinoma. Ann Surg Oncol. 2014;21(5):1678-85. https://doi.org/10.1245/ s10434-013-3466-8.

12. Chon HJ, Hyung WJ, Kim C, Park S, Kim JH, Park CH, et al. Differential prognostic implications of gastric signet ring cell carcinoma: stage adjusted analysis from a single high-volume center in asia. Ann Surg. 2017;265(5):946-53. https://doi.org/10.1097/ sla.0000000000001793.

13. Ha TK, An JY, Youn HK, Noh JH, Sohn TS, Kim S. Indication for endoscopic mucosal resection in early signet ring cell gastric cancer. Ann Surg Oncol. 2008;15(2):508-13. https://doi.org/10.1245/ s10434-007-9660-9.

14. Hyung WJ, Noh SH, Lee JH, Huh JJ, Lah KH, Choi SH, et al. Early gastric carcinoma with signet ring cell histology. Cancer. 2002;94(1):78-83.

15. Kim DY, Park YK, Joo JK, Ryu SY, Kim YJ, Kim SK, et al. Clinicopathological characteristics of signet ring cell carcinoma of the stomach. ANZ J Surg. 2004;74(12):1060-4. https://doi.org/10.11 11/j.1445-1433.2004.03268.x.

16. Otsuji E, Yamaguchi T, Sawai K, Takahashi T. Characterization of signet ring cell carcinoma of the stomach. J Surg Oncol. 1998;67(4):216-20.

17. Yokota T, Kunii Y, Teshima S, Yamada Y, Saito T, Kikuchi S, et al. Signet ring cell carcinoma of the stomach: a clinicopathological comparison with the other histological types. Tohoku J Exp Med. 1998;186(2):121-30.

18. Patel VR, Hofstetter WL, Correa AM, Agarwal A, Rashid A, Bhutani MS, et al. Signet ring cells in esophageal adenocarcinoma predict poor response to preoperative chemoradiation. Ann Thorac Surg. 2014;98(3):1064-71. https://doi.org/10.1016/j.athor acsur.2014.04.099.

19. Charalampakis N, Nogueras Gonzalez GM, Elimova E, Wadhwa R, Shiozaki H, Shimodaira Y, et al. The proportion of signet ring cell component in patients with localized gastric adenocarcinoma correlates with the degree of response to pre-operative chemoradiation. Oncology. 2016;90(5):239-47. https://doi. org/10.1159/000443506.

20. Chirieac LR, Swisher SG, Correa AM, Ajani JA, Komaki RR, Rashid A, et al. Signet-ring cell or mucinous histology after preoperative chemoradiation and survival in patients with esophageal or esophagogastric junction adenocarcinoma. Clin Can Res. 2005;11(6):2229-36. https://doi.org/10.1158/1078-0432. Ccr-04-1840.

21. Heger U, Sisic L, Nienhuser H, Blank S, Hinz U, Haag GM, et al. Neoadjuvant therapy improves outcomes in locally advanced signet-ring-cell containing esophagogastric adenocarcinomas. Ann Surg Oncol. 2018;25(8):2418-27. https://doi.org/10.1245/s1043 4-018-6541-3.

22. Heger U, Blank S, Wiecha C, Langer R, Weichert W, Lordick F, et al. Is preoperative chemotherapy followed by surgery the appropriate treatment for signet ring cell containing adenocarcinomas of the esophagogastric junction and stomach? Ann Surg Oncol. 2014;21(5):1739-48. https://doi.org/10.1245/s10434-013-3462-z.

23. van Hootegem SJM, Smithers BM, Gotley DC, Brosda S, Thomson IG, Thomas JM, et al. The impact of signet ring cell differentiation on outcome in patients with esophageal and gastroesophageal junction adenocarcinoma. Ann Surg Oncol. 2019;26(8):2375-84. https://doi.org/10.1245/s10434-019-07322 $-\mathrm{x}$. 
24. Messager M, Lefevre JH, Pichot-Delahaye V, Souadka A, Piessen $\mathrm{G}$, Mariette $\mathrm{C}$, et al. The impact of perioperative chemotherapy on survival in patients with gastric signet ring cell adenocarcinoma: a multicenter comparative study. Ann Surg. 2011;254(5):684-93. https://doi.org/10.1097/SLA.0b013e3182352647.

25. Mariette C, Carneiro F, Grabsch HI, van der Post RS, Allum W, de Manzoni G, et al. Consensus on the pathological definition and classification of poorly cohesive gastric carcinoma. Gastric Cancer. 2019;22(1):1-9. https://doi.org/10.1007/s10120-018-0868-0.

26. Lauren $P$. The two histological main types of gastric carcinoma: diffuse and so-called intestinal-type carcinoma an attempt at a histo-clinical classification. Acta Pathol Microbiol Scand. 1965;64:31-49. https://doi.org/10.1111/apm.1965.64.1.31.

27. Oota K, Sobin LH. Histological typing of gastric and oesophageal tumours. 1st ed. WHO International histological classification of tumours, No 18. Geneva. 1977.

28. Bosman FT, Carneiro F, Hruban RH, Theise ND (eds). WHO classification of tumours of the digestive system. 4th ed. 2010.

29. Watanabe H, Jass JR, Sobin LH (eds). Histological typing of oesophageal and gastric tumours. 2nd ed. WHO: International histological classification of tumours. Springer-Verlag, Berlin Heidelberg; 1990.

30. Hamilton SR, Aaltonen LA, (eds). Pathology and Genetics of tumours of the digestive system. 3rd ed. WHO classification of tumours: IARC press Lyon; 2000.

31. WHO Classification of Tumours Editorial Board (eds). Digestive system tumours. 5th ed. Lyon: IARC Press; 2019.

32. Hewitt LC, Inam IZ, Saito Y, Yoshikawa T, Quaas A, Hoelscher A, et al. Epstein-Barr virus and mismatch repair deficiency status differ between oesophageal and gastric cancer: A large multi-centre study. Eur J Cancer 2018;94:104-14. https://doi. org/10.1016/j.ejca.2018.02.014.

33. Bamba M, Sugihara H, Kushima R, Okada K, Tsukashita S, Horinouchi M, et al. Time-dependent expression of intestinal phenotype in signet ring cell carcinomas of the human stomach. Virchows Arch. 2001;438(1):49-56.

34. Tsukashita S, Kushima R, Bamba M, Nakamura E, Mukaisho $\mathrm{K}$, Sugihara $\mathrm{H}$, et al. Beta-catenin expression in intramucosal neoplastic lesions of the stomach. Comparative analysis of adenoma/dysplasia, adenocarcinoma and signet-ring cell carcinoma. Oncology. 2003;64(3):251-8. https://doi. org/10.1159/000069310.

35. Aihara R, Mochiki E, Kamiyama Y, Kamimura H, Asao T, Kuwano $\mathrm{H}$. Mucin phenotypic expression in early signet ring cell carcinoma of the stomach: its relationship with the clinicopathologic factors. Dig Dis Sci. 2004;49(3):417-24.

36. Aihara R, Mochiki E, Nakabayashi T, Akazawa K, Asao T, Kuwano H. Clinical significance of mucin phenotype, beta-catenin and matrix metalloproteinase 7 in early undifferentiated gastric carcinoma. Br J Surg. 2005;92(4):454-62.

37. Ohkura Y, Kawamata H, Chibana Y, Ichikawa K, Fujii S, Tomita $\mathrm{S}$, et al. Histopathological study of small $(\% 3 \mathrm{c} 2 \mathrm{~cm})$ gastric carcinoma with signet-ring cell component: significance of the admixed glandular components. Int J Surg Pathol. 2005;13(2):197-203. https://doi.org/10.1177/106689690501300211.

38. Tian MM, Zhao AL, Li ZW, Li JY. Phenotypic classification of gastric signet ring cell carcinoma and its relationship with clinicopathologic parameters and prognosis. World J Gastroenterol. 2007;13(23):3189-98.

39. Nakajima T, Uehara T, Maruyama Y, Iwaya M, Kobayashi Y, Ota H. Distribution of Lgr5-positive cancer cells in intramucosal gastric signet-ring cell carcinoma. Pathol Int. 2016;66(9):518-23. https://doi.org/10.1111/pin.12451.

40. Xiong ZF, Shi J, Fu ZH, Wan HP, Tu LX. Phenotypic classification of gastric signet ring cell carcinoma and its relationship with
K-ras mutation. Genet Mol Res. 2017. https://doi.org/10.4238/ gmr16029181.

41. Terada T. An immunohistochemical study of primary signet-ring cell carcinoma of the stomach and colorectum: II. Expression of MUC1, MUC2, MUC5AC, and MUC6 in normal mucosa and in 42 cases. Int J Clin Exp Pathol. 2013;6(4):613-21.

42. Terada T. An immunohistochemical study of primary signet-ring cell carcinoma of the stomach and colorectum: III. Expressions of EMA, CEA, CA19-9, CDX-2, p53, Ki-67 antigen, TTF-1, vimentin, and p63 in normal mucosa and in 42 cases. Int $\mathrm{J}$ Clin Exper Pathol. 2013;6(4):630-8.

43. Fujiyoshi Y, Eimoto T. Chromogranin A expression correlates with tumour cell type and prognosis in signet ring cell carcinoma of the stomach. Histopathology. 2008;52(3):305-13. https://doi. org/10.1111/j.1365-2559.2007.02950.x.

44. Bakkelund K, Fossmark R, Nordrum I, Waldum H. Signet ring cells in gastric carcinomas are derived from neuroendocrine cells. J Histochem Cytochem. 2006;54(6):615-21.

45. Santini D, Bazzocchi F, Mazzoleni G, Ricci M, Viti G, Marrano D et al (1987) Signet-ring cells in advanced gastric cancer. A clinical, pathological and histochemical study. Acta Pathol Microbiol Immunol Scand A 95(5):225-231

46. Yamachika T, Inada K, Fujimitsu Y, Nakamura S, Yamamura Y, Kitou T, et al. Intestinalization of gastric signet ring cell carcinomas with progression. Virchows Arch. 1997;431(2):103-10.

47. Akyurek N, Akyol G, Dursun A, Yamac D, Gunel N. Expression of MUC1 and MUC2 mucins in gastric carcinomas: their relationship with clinicopathologic parameters and prognosis. Pathol Res Pract. 2002;198(10):665-74. https://doi.org/10.1078/0344-033800318.

48. Baldus SE, Zirbes TK, Engel S, Hanisch FG, Monig SP, Lorenzen J, et al. Correlation of the immunohistochemical reactivity of mucin peptide cores MUC1 and MUC2 with the histopathological subtype and prognosis of gastric carcinomas. Int J Cancer. 1998;79(2):133-8.

49. Bartley AN, Rashid A, Fournier KF, Abraham SC. Neuroendocrine and mucinous differentiation in signet ring cell carcinoma of the stomach: evidence for a common cell of origin in composite tumors. Hum Pathol. 2011;42(10):1420-9. https://doi. org/10.1016/j.humpath.2010.12.008.

50. Kim YH, Park JH, Park CK, Kim JH, Lee SK, Lee YC, et al. Histologic purity of signet ring cell carcinoma is a favorable risk factor for lymph node metastasis in poorly cohesive, submucosainvasive early gastric carcinoma. Gastric Cancer. 2017;20(4):58390. https://doi.org/10.1007/s10120-016-0645-x.

51. Ilhan O, Han U, Onal B, Celik SY. Prognostic significance of MUC1, MUC2 and MUC5AC expressions in gastric carcinoma. Turk J Gastroenterol. 2010;21(4):345-52.

52. Chu PG, Weiss LM. Immunohistochemical characterization of signet-ring cell carcinomas of the stomach, breast, and colon. Am J Clin Pathol. 2004;121(6):884-92. https://doi.org/10.1309/ a09e-rymf-r64n-erdw.

53. Kubota K, Yamada S, Ito M, Nakamura W, Nagayo T. Cytoplasmic leucine naphthylamidase activity expressed in signet-ring cell carcinoma of the stomach. J Natl Cancer Inst. 1977;59(6):1599-604.

54. Akamatsu T, Katsuyama T. Histochemical demonstration of mucins in the intramucosal laminated structure of human gastric signet ring cell carcinoma and its relation to submucosal invasion. Histochem J. 1990;22(8):416-25.

55. Tatematsu M, Ichinose M, Miki K, Hasegawa R, Kato T, Ito N. Gastric and intestinal phenotypic expression of human stomach cancers as revealed by pepsinogen immunohistochemistry and mucin histochemistry. Acta Pathol Jpn. 1990;40(7):494-504.

56. Tatematsu M, Hasegawa R, Ogawa K, Kato T, Ichinose M, Miki K, et al. Histogenesis of human stomach cancers based on 
assessment of differentiation. J Clin Gastroenterol. 1992;14(Suppl 1):S1-7.

57. Takenoshita S, Hashizume T, Katoh R, Koitabashi H, Nagamachi Y. Mucin production and subsequent interstitial fibrosis in gastriccancer with signet-ring cells. Oncol Rep. 1994;1(3):537-41.

58. Nguyen MD, Plasil B, Wen P, Frankel WL. Mucin profiles in signet-ring cell carcinoma. Arch Pathol Lab Med. 2006;130(6):799_ 804. https://doi.org/10.1043/1543-2165(2006)130[799:Mpisc c]2.0.Co;2.

59. Sakamoto H, Yonezawa S, Utsunomiya T, Tanaka S, Kim YS, Sato E. Mucin antigen expression in gastric carcinomas of young and old adults. Hum Pathol. 1997;28(9):1056-65.

60. Fujimoto A, Ishikawa Y, Ishii T, Yamada A, Igarashi Y, Ohmoto $\mathrm{Y}$, et al. Differences between gastric signet-ring cell carcinoma and poorly differentiated adenocarcinoma: a comparison of histopathologic features determined by mucin core protein and trefoil factor family peptide immunohistochemistry. Pathol Int. 2017;67(8):398-403. https://doi.org/10.1111/pin.12559.

61. Gurbuz Y, Kahlke V, Kloppel G. How do gastric carcinoma classification systems relate to mucin expression patterns? An immunohistochemical analysis in a series of advanced gastric carcinomas. Virchows Arch. 2002;440(5):505-11. https://doi.org/10.1007/ s00428-002-0620-2.

62. Zhang HK, Zhang QM, Zhao TH, Li YY, Yi YF. Expression of mucins and E-cadherin in gastric carcinoma and their clinical significance. World J Gastroenterol. 2004;10(20):3044-7.

63. Yonezawa S, Kitajima S, Higashi M, Osako M, Horinouchi M, Yokoyama S, et al. A novel anti-MUC1 antibody against the
MUC1 cytoplasmic tail domain: use in sensitive identification of poorly differentiated cells in adenocarcinoma of the stomach. Gastric Cancer. 2012;15(4):370-81. https://doi.org/10.1007/s1012 0-011-0125-2.

64. Seki T, Ito T, Kawachi H, Sekine M, Funata N, Takizawa T. Relationship between mucin expression of gastric intramucosal signet ring cell carcinoma and its background mucosa. J Med Dent Sci. 2009;56(1):25-35.

65. Chiaravalli AM, Klersy C, Tava F, Manca R, Fiocca R, Capella $\mathrm{C}$, et al. Lower- and higher-grade subtypes of diffuse gastric cancer. Hum Pathol. 2009;40(11):1591-9. https://doi.org/10.1016/j. humpath.2009.04.004.

66. Yoshikawa A, Inada Ki KI, Yamachika T, Shimizu N, Kaminishi M, Tatematsu M. Phenotypic shift in human differentiated gastric cancers from gastric to intestinal epithelial cell type during disease progression. Gastric Cancer. 1998;1(2):134-41. https://doi. org/10.1007/s101200050007.

67. Yamada T, Yoshikawa T, Taguri M, Hayashi T, Aoyama T, SueLing HM, et al. The survival difference between gastric cancer patients from the UK and Japan remains after weighted propensity score analysis considering all background factors. Gastric Cancer. 2016;19(2):479-89. https://doi.org/10.1007/s10120-015-0480-5.

Publisher's Note Springer Nature remains neutral with regard to jurisdictional claims in published maps and institutional affiliations.

\section{Affiliations}

K. G. P. Kerckhoffs ${ }^{1}$ - D. H. W. Liu ${ }^{1}$ L. Saragoni ${ }^{2} \cdot$ R. S. van der Post ${ }^{3} \cdot$ R. Langer ${ }^{4} \cdot$ M. Bencivenga $^{5} \cdot$ M. Iglesias $^{6}$.

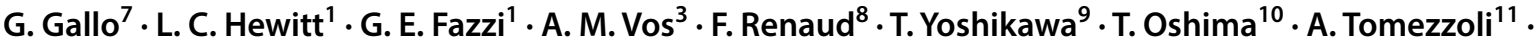

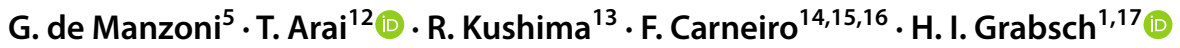

1 Department of Pathology, GROW School for Oncology and Developmental Biology, Maastricht University Medical Center+, P. Debyelaan 25, 6229HX Maastricht, The Netherlands

2 Pathology Unit, Morgagni-Pierantoni Hospital, Forlì, Italy

3 Department of Pathology, Radboudumc, Nijmegen, The Netherlands

4 Institute of Pathology, University of Bern, Bern, Switzerland

5 Unit of General and Upper GI Surgery, University of Verona, Verona, Italy

6 Pathology Department, Hospital del Mar, Universitat Autonoma de Barcelona, Barcelona, Spain

7 Department of Anatomic Pathology, Azienda Ospedaliero-Universitaria Policlinico di Modena, Modena, Italy

8 Department of Pathology, Univ. Lille, CNRS, Inserm, CHU Lille, UMR9020 - UMR-S 1277 - Canther - Cancer Heterogeneity, Plasticity and Resistance to Therapies, Lille, France

9 Department of Gastric Surgery, National Cancer Center Hospital, Tokyo, Japan
10 Department of Gastrointestinal Surgery, Kanagawa Cancer Center, Yokohama, Japan

11 Department of Pathology, Verona University Hospital, Verona, Italy

12 Department of Pathology, Tokyo Metropolitan Geriatric Hospital and Institute of Gerontology, Tokyo, Japan

13 Department of Pathology, Shiga University of Medical Science, Shiga, Japan

14 Institute of Molecular Pathology and Immunology at the University of Porto (Ipatimup), Porto, Portugal

15 Instituto de Investigação e Inovação em Saúde (i3S), University of Porto, Porto, Portugal

16 Pathology Department, Centro Hospitalar de São João and Faculty of Medicine, Porto, Portugal

17 Division of Pathology and Data Analytics, Leeds Institute of Medical Research at St. James's, University of Leeds, Leeds, UK 